\title{
Effects of diet-induced obesity and voluntary wheel running on the microstructure of the murine distal femur
}

\author{
Hongqiang Ma', Tuomas Turpeinen², Mika Silvennoinen ${ }^{3}$, Sira Torvinen ${ }^{3}$, Rita Rinnankoski-Tuikka ${ }^{3}$,
} Heikki Kainulainen ${ }^{3}$, Jussi Timonen ${ }^{2}$, Urho M Kujala ${ }^{1}$, Paavo Rahkila ${ }^{1}$, Harri Suominen ${ }^{1 *}$

\begin{abstract}
Background: Obesity and osteoporosis, two possibly related conditions, are rapidly expanding health concerns in modern society. Both of them are associated with sedentary life style and nutrition. To investigate the effects of diet-induced obesity and voluntary physical activity we used high resolution micro-computed tomography $(\mu C T)$ together with peripheral quantitative computed tomography $(\mathrm{pQCT})$ to examine the microstructure of the distal femoral metaphysis in mice.

Methods: Forty 7-week-old male C57BL/6J mice were assigned to 4 groups: control (C), control + running (CR), high-fat diet (HF), and high-fat diet + running (HFR). After a 21-week intervention, all the mice were sacrificed and the left femur dissected for $\mathrm{PQCT}$ and $\mu \mathrm{CT}$ measurements.

Results: The mice fed the high-fat diet showed a significant weight gain (over $70 \%$ for HF and $60 \%$ for HFR), with increased epididymal fat pad mass and impaired insulin sensitivity. These obese mice had significantly higher trabecular connectivity density, volume, number, thickness, area and mass, and smaller trabecular separation. At the whole bone level, they had larger bone circumference and cross-sectional area and higher density-weighted maximal, minimal, and polar moments of inertia. Voluntary wheel running decreased all the cortical bone parameters, but increased the trabecular mineral density, and decreased the pattern factor and structure model index towards a more plate-like structure.

Conclusions: The results suggest that in mice the femur adapts to obesity by improving bone strength both at the whole bone and micro-structural level. Adaptation to running exercise manifests itself in increased trabecular density and improved 3D structure, but in a limited overall bone growth.
\end{abstract}

\section{Background}

Bone strength/quality is not only determined by bone mineral density/mass alone but also by its geometrical structure and distribution in space. Both peripheral quantified computed tomography (pQCT) and microcomputed tomography $(\mu \mathrm{CT})$ have thus been used in recent years for rodent skeleton measurements. Since the first application of pQCT to the mouse skeleton density measurement was reported in 1996 [1], it has been frequently used to measure the volumetric bone mineral density and geometrical parameters of trabecular and

\footnotetext{
* Correspondence: harri.k.suominen@jyu.fi

${ }^{1}$ Department of Health Sciences, University of Jyväskylä, Finland

Full list of author information is available at the end of the article
}

cortical bone in vivo or ex vivo. However, due to its limited resolution, $\mathrm{pQCT}$ has failed to obtain information on the trabecular microstructure. The introduction of $\mu \mathrm{CT}$ with at best a submicrometer resolution in biomedical research has made accurate assessment of the material microstructure possible. Based on different algorithms, the 3D structure and related parameters of bone can be obtained. They describe the properties of bone better than the "golden standard" histomorphometry based on stereological assumptions.

Osteoporosis and obesity are two common complex diseases with serious health-related consequences. These two disorders of the body composition have usually been considered separately, but more recently both
C Biomed Central

(C) 2011 Ma et al; licensee BioMed Central Ltd. This is an Open Access article distributed under the terms of the Creative Commons Attribution License (http://creativecommons.org/licenses/by/2.0), which permits unrestricted use, distribution, and reproduction in any medium, provided the original work is properly cited. 
clinical and experimental data have established a close link between them [2]. Epidemiological data and animal studies indicate that these two diseases share several features including a genetic predisposition and a common progenitor cell [3], and both are influenced by nutrition and a sedentary life style [4]. Obesity is a condition of excessive body fat that causes or exacerbates the risk for developing non-insulin dependent diabetes, cardiovascular diseases, cancer, and other diseases [5], and is associated with chronic inflammatory status [6]. Osteoporosis is a disease characterized by low bone mass and structural deterioration of bone tissue, leading to bone fragility and increased susceptibility to fractures.

Nutrition, including dietary fat [7] and restricted caloric intake [8], are related to molecular markers of bone remodelling and may contribute to the risk for bonerelated diseases [9]. Diets high in saturated fat can adversely affect bone mineralization [10]. Diet components are also closely associated with obesity in both humans [11] and animals [12]. A recent genetic linkage analysis between obesity and osteoporosis has found evidence of genetic influences behind these two disorders being related and likely mapped to many of the same quantitative trait loci [13]. These linkages have also been documented in previous epidemiological investigations, where obesity has been associated with bone mass, strength and density $[14,15]$. Furthermore, there is abundant evidence that adipose tissue, as an endocrinal organ, affects bone metabolism through secreted adipokines, especially leptin $[16,17]$. Together with secreted inflammatory factors, these adipokines alter the bone microenvironment and regulate bone modelling and remodelling. However, whether these relations are positive or negative remains controversial.

In obese subjects, physical activity has been shown to be an efficient tool to treat obesity-related diseases and improve the quality of life, and also to improve bone quality in both humans [18] and animals [19]. Consistently, our previous study with twin pairs showed that long-term leisure time physical activity has positive effects on both trabecular and cortical bone [20]. In mice, voluntary wheel running was associated with increased trabecular bone mineral density [21].

Despite the complex relationships between bone, obesity and physical activity, it is clear that both obesity and physical activity affect bone metabolism. The purpose of this study was to determine how dietinduced obesity combined with voluntary exercise affects cortical and trabecular bone properties. We measured these bone properties by high resolution $\mu \mathrm{CT}$ together with $\mathrm{pQCT}$ measurements on the distal femoral metaphysis.

\section{Methods}

\section{Animals and Diets}

This study was approved by the National Animal Experiment Board, Finland. Forty 6-week-old male C57BL/6J mice were obtained from Taconic (Ejby, Denmark). The mice were housed, one per cage, in a humidity- and temperature-controlled room with a 12:12 light cycle (08.00:20.00), and allowed to adapt to their new environment for 1 week before being allocated to one of the four intervention groups: control diet $(\mathrm{C})$, control diet + voluntary running (CR), high-fat diet (HF), and high-fat diet + voluntary running (HFR).

To study the effect of voluntary wheel running exercise, animals in the CR and HFR groups were housed in custom-made cages with a running wheel (diameter 24 $\mathrm{cm}$, width $8 \mathrm{~cm}$ ) to which they had free access $24 \mathrm{~h} /$ day for 21 weeks. Total wheel revolutions were recorded daily by a magnetic switch, with the total exercise performed per day determined by multiplying the number of wheel rotations by the circumference of the wheel. $C$ and HF animals were housed in similar cages without the running wheel. The mice had continuous access to the control or high-fat diet, respectively, and to regular tap water. Body mass and food consumption were measured at two-week intervals. The control diet was a standard rodent diet, R36 (4\% fat, 55.7\% carbohydrate, $18.5 \%$ protein, $3 \mathrm{kcal} / \mathrm{g}$, Labfor, Stockholm Sweden). The high-fat diet was a lard-based purified diet, D12492 (60\% fat, $20 \%$ carbohydrate, $20 \%$ protein, $5.24 \mathrm{kcal} / \mathrm{g}$, Research Diets, Inc., USA).

\section{Glucose Tolerance and Insulin Resistance Tests}

For all the mice glucose and insulin tolerance tests (GTT and ITT, respectively) were performed at oneweek interval after 10 and 18 weeks of intervention. Briefly, mice were fasted for $5 \mathrm{~h}$ before GTT and $2 \mathrm{~h}$ before ITT. Glucose ( $2 \mathrm{~g} / \mathrm{kg}$ body mass) or insulin (0.75 U/kg BM; Humuline ${ }^{\mathbb{B}}$ Regular, Eli Lilly, Indianapolis, IN) solution was injected into the intraperitoneal cavity, followed by blood sampling from the shaved hind limb vein at time points 0,15 (ITT only), 30, 60, 90, and $120 \mathrm{~min}$. Glucose level was determined by a B-Glucose photometer (HemoCue AB, Angelholm, Sweden). Total area under the GTT (AUC-GTT) and above ITT (AUCITT) curves was calculated using the trapezoidal rule.

\section{Serum Biomarkers}

After 21 weeks of intervention, the mice were sacrificed by cervical dislocation. Blood samples were collected and sera separated after clotting for 1 hour and stored at $-70^{\circ} \mathrm{C}$ for further analysis. Concentrations of insulin, leptin, osteoprotegerin (OPG), osteocalcin, resistin, and 
plasminogen activator inhibitor-1 (PAI-1) in serum were measured using the Milliplex mouse bone metabolism panel (Millipore, Bedford, MA) according to the manufacturer's instructions.

\section{Specimen Collection}

After the mice were sacrificed, the left femur was separated and trimmed of attached soft and connective tissues, wrapped within PBS-soaked gauze, and stored frozen at $-20^{\circ} \mathrm{C}$. Liver and epididymal fat pads were surgically removed.

\section{pQCT Densitometry}

The femur was thawed overnight at $4{ }^{\circ} \mathrm{C}$ and inserted into a specially constructed plastic syringe with the shaft in the axial direction. Scanning was done with a pQCT apparatus (Stratec XCT Research SA, Stratec Medizintechnik GmbH, Pforzheim, Germany) calibrated using a hydroxyapatite standard cone phantom. A voxel size of $0.07 \times 0.07 \times 0.5 \mathrm{~mm}$ was used in all the measurements. The scout view was obtained from the entire bone for landmark detection (see Figure 1). Four slices (s1-s4) were scanned at $0.5-\mathrm{mm}$ intervals starting from $12.5 \%$ landmark. All the scanned slices were analyzed by bone analysis software (Geanie 2.1, Commit, Espoo, Finland). A threshold value of $500 \mathrm{mg} / \mathrm{cm}^{3}$ was used for the separation of trabecular and cortical bone. From s4, total bone circumference $(\mathrm{CfB})$, total bone crosssectional area (CSA), total bone mineral density (BMD) and content (BMC), density-weighted maximum (Imax), minimum (Imin), and polar moment of inertia (Ipolar) were determined. Cortical cross-sectional area (cCSA), cortical bone mineral density (cBMD) and content (cBMC), cortical thickness (ThC: using a ring model), trabecular cross-sectional area (traCSA), trabecular bone mineral density (traBMD) and content (traBMC), and marrow cross-sectional area (mCSA) were also assessed. Compressive strength index $\left(\mathrm{CSI}=\mathrm{BMD}^{2} \times \mathrm{CSA}\right)$ was determined. After the pQCT measurements, the distal half of the femur was stored at $-4^{\circ} \mathrm{C}$ and fixed with $70 \%$ ethanol for further analysis. All pQCT measurements and data analyses were performed by the same

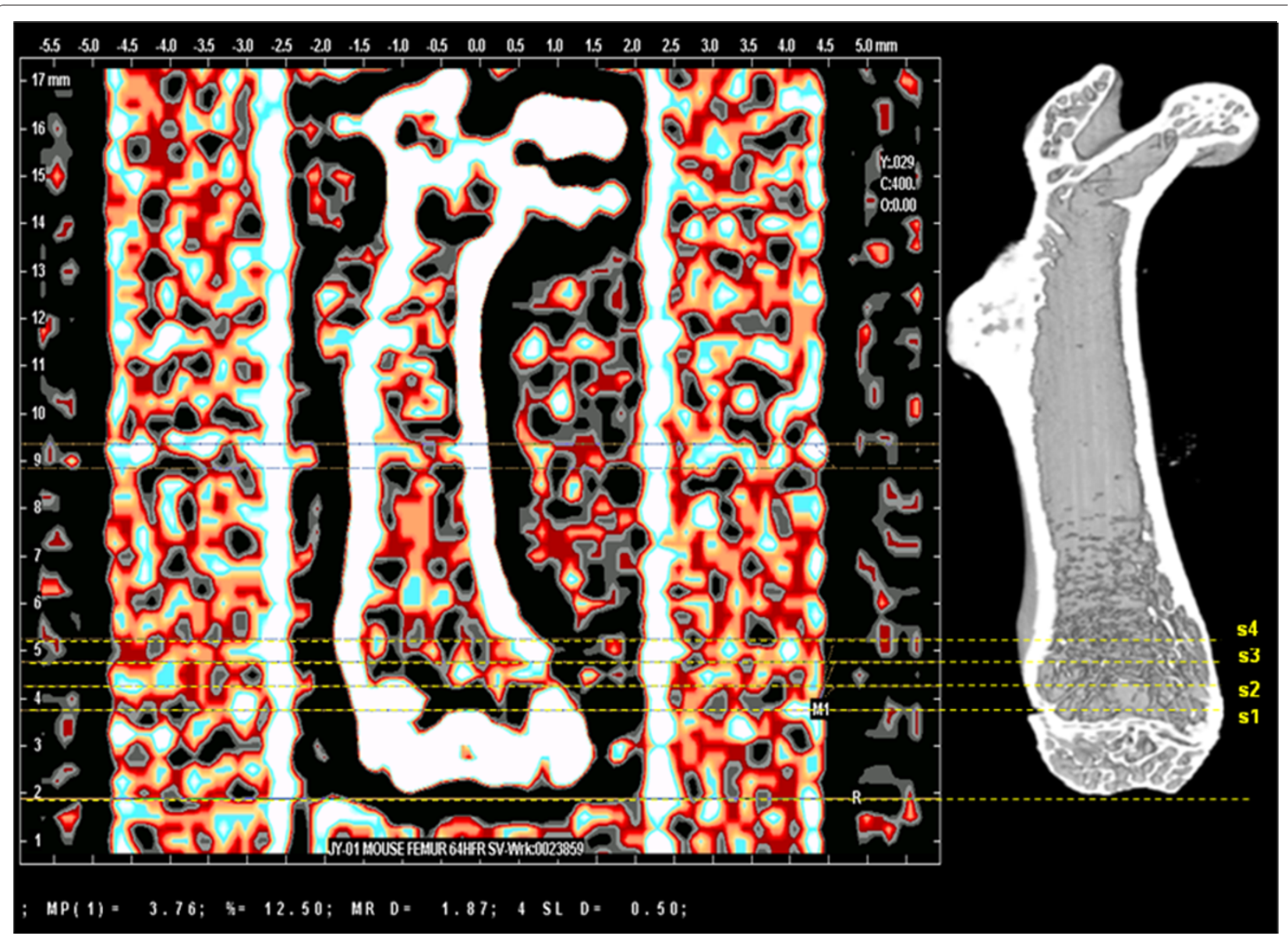

Figure $1 \mathrm{pQCT}$ (left) and $\boldsymbol{\mu C T}$ (right) overviews of a mouse femur. The position of slices (s1 - s4) scanned by the pQCT are shown. The same volume of interest was analyzed also by $\mu \mathrm{CT}$. 
individual. The coefficients of variation (CV) for repeated measurements were $2.0 \%, 0.5 \%, 2.8 \%$, and $1.2 \%$ for cTh, cBMD, traBMD, and CSA, respectively.

\section{$\mu \mathrm{CT}$ Measurements}

$\mu \mathrm{CT}$ is an imaging method that produces (in the absorption mode) a 3D density map of the sample at very high spatial resolution. The left distal femur was scanned with a Skyscan 1172 desktop $\mu$ CT scanner (Skyscan, N.V., Aartselaar, Belgium). The X-ray source was set to $90 \mathrm{kV}$ and $112 \mu \mathrm{A}$, with a voxel size of $2.8 \mu \mathrm{m}$. The projection images were acquired over an angular range of $360^{\circ}$ with an angular step of $0.4^{\circ}$ and reconstructed using a conebeam reconstruction software based on the Feldkamp algorithm yielding 1600 cross-sectional images. Four regions (s1, s2, s3, and s4) (Figure 1) were selected. Each region contained 174 cross-sectional images corresponding to the thickness measured by pQCT. For the cortical shell and trabecular structure analysis, we excluded s1, s2 and s3 due to their complicated structure (connected with fabella and condyle).

Reconstructed bone images were filtered with an Accurate Gaussian Blur filter (sigma $=0.8)$ to reduce noise. The real spatial resolution of the image is $2-3$ times the pixel size and therefore filtering with a small kernel linear filter does not significantly affect the edge quality. The binarized images were segmented from background using a simple global thresholding method. A fully automated segmentation method was developed for trabecular and cortical shell separation on the basis of previous reports [22-25]. The proposed algorithm was simply based on dilation, connection, erodation, and subtraction, and all procedures were performed using open source software ImgeJ (NIH, http://rsbweb.nih. gov/ij/). The acquired binarized image stack of trabecular bone was analyzed using a CT-Analyser (version 1.6.1). Connectivity density (Conn.D), trabecular bone volume (BV) and surface (BS), bone surface and volume ratio (BS/BV), trabecular number (Tb.N), and trabecular separation (Tb.Sp) were calculated using the Mean Intercept Length (MIL). Trabecular thickness (Tb.Th) was determined using the method of Hildebrand [26]. In addition to the computation of metric parameters, topological parameters were determined so as to describe the 3D nature of the trabecular bone. A trabecular pattern factor (Tb.Pf)), representing the amount of concave (plate-like bone) and convex (rod-like bone) structures was calculated. The higher the Tb.Pf, the more rod-like is the trabecular bone shape. A structure model index (SMI) was measured to determine the prevalence of plate-like or rod-like trabecular structures, where 0 represents "an ideal plate", 3 "a rod or cylinder", and 4 "a sphere". The degree of anisotropy (DA) of a structure, defined as the ratio between the maximal and minimal radii of the MIL ellipsoid, was calculated by superimposing parallel test lines in different directions in the 3D image. DA defines the magnitude of preferred orientation of trabeculae, i.e., the amount of bone that is aligned with the principal axis relative to the other axes. As with pQCT, all microCT measurements and data analyses were performed by the same individual with the CV values being $1.4 \%$ for BV, $3.2 \%$ for Tb.N, $4.2 \%$ for Tb.Th, and $1.2 \%$ for Tb.Sp.

\section{Statistics}

Results are expressed as mean (SD). The Shapiro-Wilk test was used to investigate within-group normality for a given parameter of interest. Levene's test was conducted to assess the homogeneity of the variance assumption. The effects of diet (with 2 levels: control and high-fat diet), running (with 2 levels: with and without voluntary wheel running), and their interaction were investigated for each dependent variable using a two-way ANOVA. With the present sample size, the mean statistical power for detecting significant $(\mathrm{p}<0.05)$ diet effect on measured bone traits was 0.88 , with four parameters showing power values less than $.70(\mathrm{tBMD}=0.67, \mathrm{CSI}=$ 0.65 , Conn.D $=0.60$ ). For significant running effect, the mean power was 0.86 , with one parameter showing a value below $70(\mathrm{tBMD}=0.64)$. A significant interaction of running by diet was found for CSI with a power of 0.70 . The trait means of groups were compared and the significance of differences was determined by post hoc testing using Tukey's HSD. When the normality or equality of variance assumptions was not met, logarithm transformations were conducted. If these parameters still did not meet normality and equality of variance, nonparametric tests were performed and Kruskal Wallis Test was used for multiple comparisons with Chi-Square. The Asymp.Sig level was set at $p<0.05$. In the Wilcoxon W test for between-group comparisons, the adjusted Asymp.Sig level was set at $p<0.008$. All the statistical analyses were performed with SPSS 15.0. A $p$-value of $<0.05$ was considered significant.

\section{Results}

Caloric Intake, Body Mass, GTT and ITT

Voluntary wheel running increased the total dietary caloric consumption as well as protein and carbohydrate intake. However, the increase was significant only in the mice on the control diet (Table 1). After 4 weeks of intervention, HF and HFR had significantly higher body mass than $C$ and $C R$. From this time point on, the body mass of mice fed the high-fat diet increased continuously. The body mass of mice fed the control diet reached a peak after 12 weeks of intervention. Finally, the mice in the HF group gained $\sim 72 \%$ of body mass and those in $\mathrm{C} \sim 25 \%$ when compared to their initial 
Table 1 Total energy consumption and the energy derived from fat, protein and carbohydrates during the 21-week intervention, and the results of the glucose and insulin tolerance tests performed at weeks 10 and 18 of the intervention

\begin{tabular}{|c|c|c|c|c|c|c|c|}
\hline \multirow[t]{2}{*}{ Basic data } & \multicolumn{2}{|c|}{ Control diet } & \multicolumn{2}{|c|}{ High-fat diet } & \multicolumn{3}{|c|}{ ANOVA ( $p$ value) } \\
\hline & $C(n=10)$ & $C R(n=10)$ & $\mathrm{HF}(n=10)$ & HFR $(n=10)$ & Diet & Running & Diet*Running \\
\hline \multicolumn{8}{|l|}{ Energy consumption } \\
\hline Total (kcal) & $1402(83)$ & $1513(76)^{a}$ & $1731(143)^{a b}$ & $1771(132)^{a b}$ & $<0.001$ & $<0.05$ & 0.330 \\
\hline Fat (kcal)\# & $56.1(3.3)$ & $60.5(3.1)^{a}$ & $1038(86)^{a b}$ & $1063(79)^{a b}$ & & & \\
\hline Protein (kcal)\# & $259(15)$ & $280(14)^{a}$ & $346(29)^{\mathrm{ab}}$ & $354(26)^{a b}$ & & & \\
\hline Carbohydrate (kcal)\# & $781(46)$ & $843(43)^{a}$ & $346(29)^{a b}$ & $354(26)^{\mathrm{ab}}$ & & & \\
\hline \multicolumn{8}{|l|}{ GTT and ITT } \\
\hline AUC_GT_10 $w^{\dagger}$ & 1087 (315) & $807(194)^{a}$ & $1448(432)^{a b}$ & $1561(559)^{a b}$ & $<0.01$ & 0.510 & 0.128 \\
\hline AUC_GTI_18W & $947(356)$ & $722(315)^{a}$ & $1527(216)^{a b}$ & $1575(466)^{a b}$ & $<0.01$ & 0.428 & 0.225 \\
\hline AUC_IT_10W & $778(105)$ & $727(155)$ & $980(159)^{a b}$ & $862(242)^{b}$ & $<0.01$ & 0.131 & 0.540 \\
\hline AUC_IT__18w & $812(183)$ & 767 (169) & $992(190)^{a b}$ & $968(245)^{b}$ & $<0.01$ & 0.586 & 0.869 \\
\hline Glucose $_{10 w \text {-fasting }}(\mathrm{mmol} / \mathrm{L})$ & $9.08(0.68)$ & $8.29(0.97)^{a}$ & $9.74(0.58)^{b}$ & $9.26(0.92)^{b}$ & $<0.01$ & $<0.05$ & 0.547 \\
\hline Glucose $_{18 w \text {-fasting }}(\mathrm{mmol} / \mathrm{L})$ & $9.26(1.15)$ & $8.38(0.92)^{a}$ & $10.3(1.1)^{\mathrm{ab}}$ & $10.3(0.9)^{a b}$ & $<0.01$ & 0.168 & 0.197 \\
\hline
\end{tabular}

\#Wilcoxon W test for between group comparisons, ${ }^{\dagger}$ Logarithm transformation for ANOVA. ${ }^{a} p<0.05$ vs $C ;{ }^{b} p<0.05$ vs CR

weight, while the runners gained slightly less body mass, HFR $\sim 64 \%$ and CR 23\% (Figure 2A) [21]. Figure 2B shows that the obese mice had significantly lower liver mass relative to body mass than the mice fed with the control diet. Under the control diet, running significantly increased relative liver mass. Consistent with their increased body mass, the obese mice had higher relative epididymal fat pad mass than their normalweight counterparts (Figure 2C).

As expected, the obese mice in HF and HFR had significantly impaired glucose tolerance and insulin sensitivity compared to the mice in $\mathrm{C}$ and $\mathrm{CR}$. Voluntary wheel running significantly decreased AUC-GTT in the mice on the control diet, but no significant runninginduced changes were found in AUC-ITT. These findings were consistent with fasting plasma glucose levels, which were lower in CR than in C (Table 1).

\section{Wheel-Running Distance}

Both CR and HFR reached their maximum running distance after 4 weeks of intervention, with a gradual decline thereafter. The average daily distances in CR and HFR were 3.48 (1.34) and $3.13(1.13) \mathrm{km}$, respectively, with no significant differences between the groups. We have not found any significant differences in the cumulative running distance between CR and HFR, but voluntary exercise training improved the running capacity, especially in the HFR group [21].

\section{Serum Biomarkers}

Diet showed a significant main effect on serum insulin (Figure 2D), leptin (Figure 2E), osteoprotegerin (Figure 2F), PAI-1 (Figure 2H), and resistin (Figure 2I), but not on osteocalcin (Figure 2G). The obese mice had significantly higher levels of these biomarkers compared to the mice fed with the control diet.

\section{Effects of Diet-Induced Obesity and Voluntary Running on Bone}

1) Obese mice had larger and stronger distal metaphysis with more abundant and thicker trabecular bone.

Bone traits measured by pQCT are shown in Table 2. The obese mice had larger bone size (CfB and CSA), higher BMC and higher Imax, Imin, and Ipolar, but lower BMD. Larger traCSA and higher traBMC were also found in the obese mice.

Table 3 shows the $3 \mathrm{D}$ trabecular variables measured by $\mu \mathrm{CT}$ at the same site as pQCT. The obese mice had higher $\mathrm{BV}$ and $\mathrm{BS}$, a lower $\mathrm{BS} / \mathrm{BV}$ ratio, higher $\mathrm{Tb}$. Th and Tb.N, smaller Tb.Sp, and higher Conn.D. Consistently with the numerical data, representative 3D images of the $\mu \mathrm{CT}$ scans from the distal metaphysic of HF and HFR animals (Figure 3, lower panel) show that the obese mice have a more abundant, thicker, and wellconnected trabecular structure compared to their normal-weight counterparts.

2) Voluntary wheel running decreased all the cortical parameters, but increased trabecular mineral density and improved trabecular microstructure.

The runners had smaller cCSA, lower cBMD and cBMC, thinner $\mathrm{CTh}$, but higher traBMD than their counterparts, especially on the control diet (Table 2).

The $\mu \mathrm{CT}$ measurements (Table 3 ) showed that the runners had smaller Tb.Pf and SMI, indicating a more plate-like structure (Figure 3, right panel). This was more evident in mice fed with the high-fat diet.

A significant interaction between voluntary wheel running and diet on the compressive strength index was 


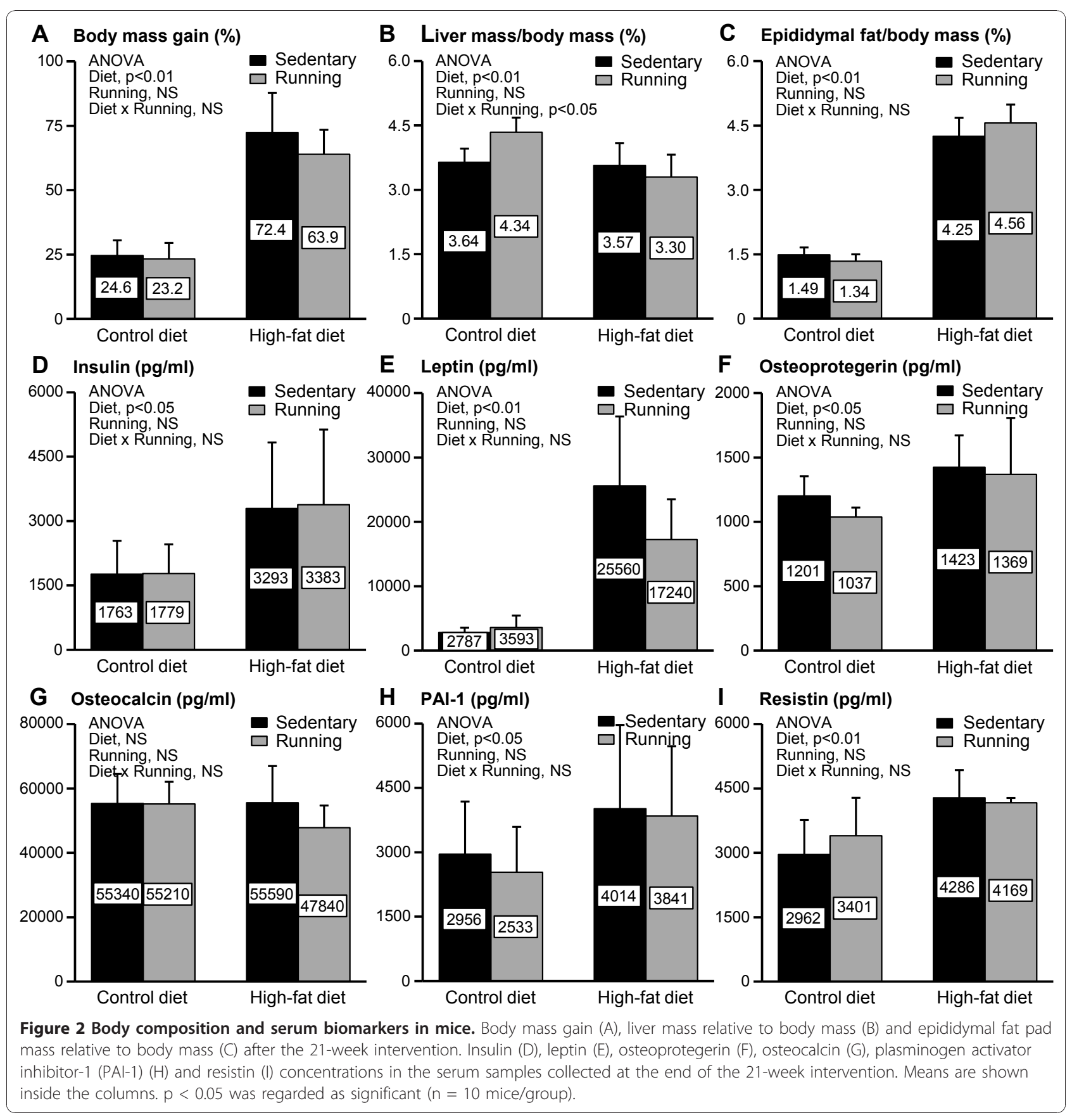

found. Under control diet, voluntary wheel running decreased CSI (Table 2).

\section{Discussion}

It is well known that trabecular bone strength is determined not only by the amount of composite material (mineral, protein and water) but also the distribution of these materials (size, area, structural properties). A number of advantages, such as more abundant, thicker, well-connected, and plate-like trabeculae, confer a stronger trabecular bone compartment [27-30]. In the present study we demonstrated that diet-induced obese mice had a larger and stronger femoral metaphysis with more abundant and thicker trabecular bone. Voluntary wheel running decreased all of the measured cortical parameters, but increased trabecular bone mineral density and improved the 3D micro-structure.

Numerous data have shown that obesity is closely associated with dietary fat intake and sedentary life style [31,32]. A close link between body mass and bone mass 
Table 2 Cortical and trabecular parameters measured by PQCT from the distal metaphysis of mouse femur dissected after 21-week intervention

\begin{tabular}{|c|c|c|c|c|c|c|c|}
\hline \multirow[t]{2}{*}{$\mathrm{pQCT}$} & \multicolumn{2}{|c|}{ Control diet } & \multicolumn{2}{|c|}{ High-fat diet } & \multirow[b]{2}{*}{ Diet } & \multicolumn{2}{|c|}{ ANOVA ( $p$ value) } \\
\hline & $C(n=10)$ & $C R(n=10)$ & HF $(n=9)$ & $\operatorname{HFR}(n=9)$ & & Running & Diet*Running \\
\hline CfB $(\mathrm{mm})$ & $6.80(0.15)$ & $6.61(0.28)$ & $7.19(0.25)^{\mathrm{ab}}$ & $7.18(0.35)^{a}$ & $<0.01$ & 0.252 & 0.291 \\
\hline $\mathrm{CSA}\left(\mathrm{mm}^{2}\right)$ & $2.85(0.14)$ & $2.68(0.18)$ & $3.11(0.31)^{b}$ & $3.16(0.35)^{b}$ & $<0.01$ & 0.491 & 0.190 \\
\hline $\mathrm{BMD}\left(\mathrm{mg} / \mathrm{cm}^{3}\right)$ & $505(13)$ & $492(13)$ & $489(14)$ & $478(20)^{a}$ & $<0.01$ & $<0.05$ & 0.806 \\
\hline $\mathrm{BMC}(\mathrm{mg} / \mathrm{mm})$ & $1.44(0.07)$ & $1.32(0.09)^{a}$ & $1.52(0.11)^{b}$ & $1.51(0.15)^{b}$ & $<0.01$ & 0.077 & 0.114 \\
\hline \multicolumn{8}{|l|}{ Biomechanics } \\
\hline $\operatorname{Imax}(\mathrm{mg} \cdot \mathrm{cm})$ & $867(71)$ & 763 (113) & $1025(124)^{\mathrm{ab}}$ & $1001(171)^{\mathrm{b}}$ & $<0.01$ & 0.129 & 0.336 \\
\hline $\operatorname{Imin}(\mathrm{mg} \cdot \mathrm{cm})$ & $255(26)$ & $219(25)$ & $298(45)^{\mathrm{b}}$ & $295(65)^{b}$ & $<0.01$ & 0.179 & 0.268 \\
\hline Ipolar (mg·cm) & $1125(95)$ & $982(134)$ & $1323(164)^{a b}$ & $1294(233)^{b}$ & $<0.01$ & 0.120 & 0.300 \\
\hline $\mathrm{CSI} \times 10^{3}\left(\mathrm{~g}^{2} / \mathrm{cm}^{4}\right)$ & $6.77(0.46)$ & $5.87(0.55)^{\mathrm{a}}$ & $6.79(0.53)$ & $6.81(0.73)$ & $<0.05$ & $<0.05$ & $<0.05$ \\
\hline \multicolumn{8}{|l|}{ Cortex } \\
\hline $\mathrm{cCSA}\left(\mathrm{mm}^{2}\right)$ & $1.23(0.11)$ & $1.06(0.09)^{a}$ & $1.21(0.09)^{b}$ & $1.17(0.11)$ & 0.142 & $<0.01$ & 0.062 \\
\hline $\mathrm{cBMD}\left(\mathrm{mg} / \mathrm{cm}^{3}\right)$ & $779(11)$ & $757(23)$ & 770 (19) & $752(31)^{a}$ & 0.332 & $<0.01$ & 0.820 \\
\hline $\mathrm{cBMC}(\mathrm{mg} / \mathrm{mm})$ & $0.95(0.09)$ & $0.80(0.08)^{a}$ & $0.93(0.07)^{b}$ & $0.88(0.12)$ & 0.334 & $<0.01$ & 0.096 \\
\hline cTh $(\mu \mathrm{m})$ & $139(23)$ & $110(14)^{a}$ & $129(12)^{b}$ & $120(18)^{a}$ & 0.866 & $<0.01$ & 0.103 \\
\hline \multicolumn{8}{|l|}{ Trabeculae } \\
\hline $\operatorname{traCSA}\left(\mathrm{mm}^{2}\right)$ & $1.63(0.11)$ & $1.62(0.12)$ & $1.90(0.26)^{\mathrm{ab}}$ & $1.99(0.32)^{\mathrm{ab}}$ & $<0.01$ & 0.596 & 0.522 \\
\hline $\operatorname{traBMD}\left(\mathrm{mg} / \mathrm{cm}^{3}\right)$ & $298(11)$ & $317(10)^{\mathrm{a}}$ & $308(12)$ & $314(12)^{a}$ & 0.431 & $<0.01$ & 0.113 \\
\hline $\operatorname{traBMC}(\mathrm{mg} / \mathrm{mm})$ & $0.49(0.04)$ & $0.51(0.04)$ & $0.58(0.08)^{a}$ & $0.63(0.10)^{\mathrm{ab}}$ & $<0.01$ & 0.121 & 0.888 \\
\hline $\mathrm{mCSA}\left(\mathrm{mm}^{2}\right)$ & $0.28(0.06)$ & $0.29(0.05)$ & $0.36(0.10)$ & $0.28(0.10)$ & 0.261 & 0.235 & 0.147 \\
\hline
\end{tabular}

Results are mean (SD) and $\mathrm{p}<0.05$ was considered as significant. $(\mathrm{C}=$ control diet, $\mathrm{CR}=$ control diet + voluntary running, $\mathrm{HF}=60 \%$ fat diet, $\mathrm{HFR}=60 \%$ fat diet + voluntary running).

${ }^{\mathrm{a}} p<0.05$ vs $\mathrm{C} ;{ }^{\mathrm{b}} p<0.05$ vs $\mathrm{CR}$.

$[17,33]$ and increased risk for osteoporotic fracture due to low body and thus bone mass [34] has been reported. Our study also found a positive relationship between body mass and bone mass. Increased body mass requires stronger bone; this can be effectively realized through distributing bone mass further from the center of mass rather than dramatically increasing bone density. In our study, although total bone mineral density was decreased to some extent, the enlarged marrow cavity and increased total bone cross-sectional area resulted in a larger and stronger bone as indicated by the increased density-weighted moment of inertia (bending strength). This suggests that endosteal resorption and periosteal formation were enhanced in the obese mice. However, the effects of body mass on the skeleton remain controversial although well documented in obese subjects in previous studies $[35,36]$. Some studies have shown that obese subjects have weaker bone to bear their over-

Table 3 Trabecular parameters measured by $\mu \mathrm{CT}$ from the distal metaphysis of mouse femur dissected after 21 -week intervention.

\begin{tabular}{|c|c|c|c|c|c|c|c|}
\hline \multirow[t]{2}{*}{$\mu C T$} & \multicolumn{2}{|c|}{ Control diet } & \multicolumn{2}{|c|}{ High-fat diet } & \multicolumn{3}{|c|}{ ANOVA ( $p$ value) } \\
\hline & $C(n=8)$ & $C R(n=9)$ & $\mathrm{HF}(\mathrm{n}=7)$ & HFR $(n=7)$ & Diet & Running & Diet*Running \\
\hline Conn.D $\left(\mathrm{mm}^{-3}\right)$ & 337 (129) & 367 (105) & 466 (138) & $415(88)$ & $<0.05$ & 0.810 & 0.339 \\
\hline $\mathrm{BV}\left(10^{-1} \mathrm{~mm}^{3}\right)$ & $0.093(0.015)$ & $0.103(0.035)$ & $0.112(0.027)$ & $0.146(0.034)^{a b}$ & $<0.01$ & 0.069 & 0.333 \\
\hline $\mathrm{BS}\left(\mathrm{mm}^{2}\right)$ & $1.59(0.24)$ & $1.70(0.52)$ & $1.85(0.39)$ & $2.23(0.37)^{a b}$ & $<0.05$ & 0.106 & 0.363 \\
\hline $\mathrm{BS} / \mathrm{BV}\left(\mathrm{mm}^{-1}\right)$ & $171(6)$ & $167(10)$ & $160(10)$ & $154(11)^{\mathrm{ab}}$ & $<0.05$ & 0.143 & 0.741 \\
\hline Tb.Pf $\left(\mathrm{mm}^{-1}\right)$ & $72.8(3.4)$ & $69.2(6.1)$ & $72.1(7.0)$ & $63.9(6.2)^{\mathrm{ac}}$ & 0.165 & $<0.01$ & 0.260 \\
\hline SMI & $2.60(0.07)$ & $2.54(0.11)$ & $2.74(0.12)^{b}$ & $2.53(0.11)^{c}$ & 0.089 & $<0.01$ & 0.061 \\
\hline Tb.Th ( $\mu \mathrm{m})$ & $23.7(1.2)$ & $23.7(1.2)$ & $26.1(0.9)^{a b}$ & $25.3(1.7)^{\mathrm{ab}}$ & $<0.01$ & 0.446 & 0.388 \\
\hline Tb.N $\left(\mathrm{mm}^{-1}\right)$ & $0.288(0.020)$ & $0.330(0.112)$ & $0.339(0.078)$ & $0.429(0.090)^{a b}$ & 0.068 & 0.158 & 0.290 \\
\hline Tb.Sp ( $\mu m)$ & $429(4)$ & $428(9)$ & $418(10)$ & $414(13)^{a b}$ & $<0.01$ & 0.352 & 0.627 \\
\hline DA & $3.52(1.49)$ & $3.72(1.15)$ & $4.08(1.52)$ & $3.73(1.36)$ & 0.575 & 0.883 & 0.587 \\
\hline
\end{tabular}

Values are mean (SD) and $\mathrm{p}<0.05$ was considered as significant. $(\mathrm{C}=$ control diet, $\mathrm{CR}=$ control diet + voluntary running, $\mathrm{HF}=60 \%$ fat diet, $\mathrm{HFR}=60 \%$ fat diet + voluntary running)

${ }^{a} p<0.05$ vs $C ;{ }^{b} p<0.05$ vs $C R ;{ }^{c} p<0.05$ vs HF 


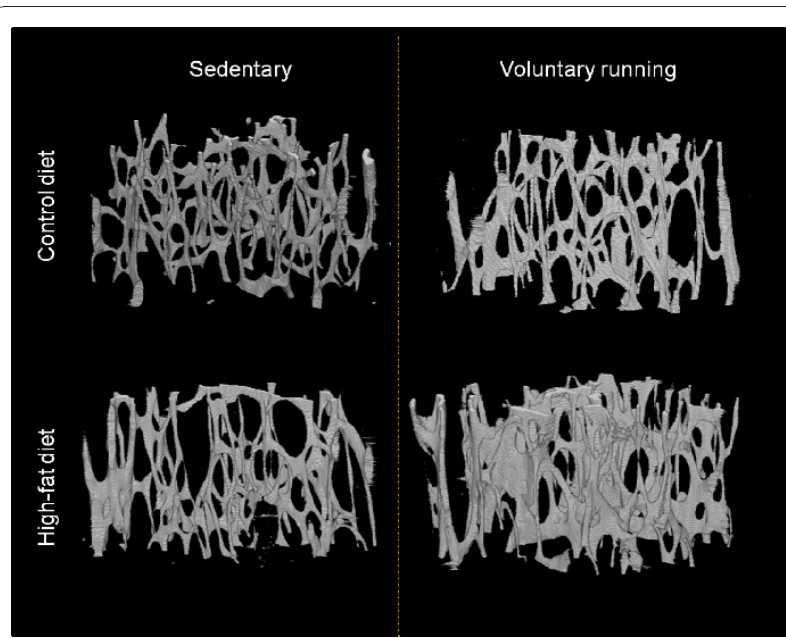

Figure 3 Representative 3D structure of the distal metaphysis of mouse femur. A rod-like trabecular structure in animals under control diet with the access to wheel running, but a more plate-like structure in HFR animals was found.

weight body mass compared to normal counterparts in both humans and animals $[37,38]$. In our study, after adjusting for body mass (unpublished data), no significant differences in bone traits between the obese and normal weight mice were found. This suggests increased bone strength through enlarged cross-sectional area thus distributing bone mass further from the centre of mass to adapt to the increase in body mass.

In order to further elucidate the effect of obesity and physical activity on bone, we separately estimated the trabecular and cortical bone compartments. It is well known that trabecular bone is the primary target for anabolic or catabolic factors and the most active bone site. The obese mice had larger trabecular area and higher trabecular bone mass than the control mice. In a recent report [39], the authors found increased SMI, decreased Conn.D, and similar Tb.Th in the proximal tibia in diet-induced obese mice. Similarly, we found increased SMI, but increased Conn.D and thicker trabeculae in the distal femur. These discrepancies could be explained by the differences in skeleton sites and our more accurate method of segmentation and higher resolution $(2.8 \mu \mathrm{m})$, which could preserve natural structure and detect even tiny connections. The cortical parameters studied (cCSA, cBMD, cBMC, and cTh,) were not significantly influenced by diet-induced obesity, as also found in a previous study [39]. However, some studies have shown positive effects of diet-induced obesity on cortical bone size [40], while negative effects on cortical bone mass [41] and size-independent mechanical properties [40] have also been suggested. These controversial results may be due to differences in animal age and the skeleton site measured as well as different measuring techniques.

Bone is a dynamic structure monitored by both intrinsic (body mass, hormone, cytokine, and other intrinsic factors) and extrinsic factors (environmental factors including physical activity, life style, etc.). On the one hand, the effect of diet-induced obesity on bone could be explained by alteration in the intrinsic mechanical loading environment caused by the increase in body mass. On the other hand, adipose tissue is regarded not just as a passive tissue for the storage of excess energy in the form of triglycerides, but also as an active endocrine organ secreting a variety of biologically active molecules, for example, leptin [42], resistin [43] and adiponectin [44]. A cascade of events such as intense conversion of androgens into estrogens occurring in adipose tissue, alterations in other hormones or cytokines, and hyperinsulinemia may influence the bone microenvironment and increase bone mass [17]. The elevated plasma leptin level in diet-induced obesity is a predictor of body mass accrual in different species $[12,45,46]$. The serum leptin level also regulates bone mass [47]. However, the results of published studies on the effects of leptin level on bone are complex and controversial [42]. Resistin is a controversial inflammatory-related factor [48], which also influences both osteoclast and osteoblast activity, resulting in increased bone remodelling [43]. We found higher plasma leptin and resistin levels in obese mice, suggesting that plasma leptin and resistin levels have a positive effect on bone. However, their effects on bone mass and strength were the opposite, bone mass and strength showing a positive association with plasma leptin level and a negative association with resistin level (unpublished data). However, increased bone mass with increased body mass independent of leptin was also reported in a recent study [33]. So far, the mechanism of interaction between bone metabolism and resistin remains unclear.

The development of obesity is associated with chronic inflammatory status, coinciding with significantly increased macrophage infiltration in adipose tissue and the expression of inflammatory cytokines, such as TNF$\alpha$, IL-6, monocyte chemotactic protein- 1 , and plasminogen activator inhibitor type-1 (PAI-1) [6]. All of these inflammatory reactions are considered to be responsible for the majority of the obesity-related syndromes. Not surprisingly, this inflammatory status also influences bone metabolism through altering the micro-environment surrounding the bone cells. Over expression of PAI-1 increased bone strength and mineralization in an age- and gender-specific manner [49]. Here, we found that a higher level of PAI-1 in obese mice correlated significantly with trabecular thickness, suggesting that PAI1 had a positive effect on bone. In addition to these 
altered adipokins and inflammatory factors, we also detected higher levels of osteoprotegerin that is a bone resorption inhibitor [50]. Together with the aforementioned factors, higher body weight may increase bone strength by shifting bone remodelling towards more active bone formation.

In order to investigate possible intervention methods, we also examined the effects of voluntary exercise. Here we found that voluntary wheel running was associated with a non-significant reduction in body mass with a concomitant improvement in glucose tolerance and insulin sensitivity and an increase in relative liver mass. Further studies are needed to find out whether the relative increase in liver mass in runners is associated with factors such as increased protein synthesis or glycogen storage. The minor reduction in body mass was not due to reduction in dietary intake. In fact, the runners consumed slightly more energy than their sedentary counterparts. Thus, the reduction in body mass was secondary to the increase in exercise-associated energy expenditure.

Physical activity has been shown to associate with bone mass and strength and to have positive effects on bone properties $[51,52]$. In obese subjects, physical activity increased total, hip, and lumbar bone mineral content [53] and decreased plasma leptin level [54,55]. More excitingly, long-term leisure time physical activity also showed positive effects on both cortical thickness and trabecular bone after controlling for the subjects' genetic background [20]. The present study showed that voluntary exercise increased trabecular bone mineral density and improved the bone geometrical structure but led to a decrease in all of the cortical parameters. Previous animal studies have also shown positive effects of exercise on bone in different species at different ages with different types of exercises [56-59]. Most of these studies have focused on either cortical or trabecular bone mass or strength, with very few studies reporting micro-structural alteration induced by exercise. In C57BL/6J mice, from the age of six weeks onwards, trabecular volume and trabecular number are generally decreased [60] while trabecular thickness and trabecular space are increased up to an age of 24 weeks [61]. Mori et al. [62] showed that intermittent voluntary climbing in eight-week-old C57BL/6J mice increased trabecular bone volume and reduced bone resorption, partially due to initial down-regulation of marrow osteoclastogenic cells and up-regulation of osteogenic cells, while further exercise desensitized them. In our study, the voluntary running lasted for 21 weeks, thus covering the entire growth period. We found that voluntary exercise tended to increase trabecular bone volume and decreased trabecular pattern factor and structure model index, shifting trabecular bone towards a stronger, more plate-like structure. However, in agreement with our previous report [21], we found that voluntary exercised animals under control diet had lower total BMC and cortical parameters. Similar findings were also reported in the rat tibia after intensive treadmill running [63], in the mice tibia after weight-bearing running during growth [64], and in 23-week-old female C57BL/6J mice after one month of voluntary wheel running [65]. These effects might be explained by overactive modeling or remodeling of bone under continuous mechanical stimulation during growth [66-68]. However, histomorphometric analyses [63] have suggested that decreased osteoblastic activity rather than a global adaptation of bone remodeling resulted in reduced longitudinal bone growth and bone loss in young rats under strenuous training. Another possible reason may be exercise-induced weight loss, which is accompanied by a reduced mechanical strain on the skeleton and decreased need of strong bones. Consequently, although numerous data indicate that, during growth, physical activity imposes its effect on bone more efficiently, the exercise programs or activities that will optimize bone structure and strength still remain unclear [18].

\section{Conclusions}

Diet-induced obesity had positive effects on total bone mass and strength rather than on total BMD, and also positive effects on trabecular structure, whereas no effects on cortical parameters were noted. Voluntary training had protective effects on trabecular bone mineral density and 3D microstructure while limiting the overall growth of cortical bone. Voluntary training combined with dietary intervention showed more apparent effects on trabecular microstructure. These results suggest that both diet and voluntary exercise affect bone properties in a site-specific manner and that the interaction between physical activity and diet is highly complicated.

\section{Acknowledgements}

This study was funded by the Academy of Finland (Grant 124 037). Ma H. was supported by the National Graduate School of Musculoskeletal Disorders and Biomaterials, Finland. We thank Leena-Kaisa Tulla and Erkki Helkala for their excellent technical assistance.

\section{Author details}

'Department of Health Sciences, University of Jyväskylä, Finland. ${ }^{2}$ Department of Physics, University of Jyväskylä, Finland. ${ }^{3}$ Department of Biology of Physical Activity, University of Jyväskylä, Finland.

\section{Authors' contributions}

$\mathrm{HM}, \mathrm{MS}, \mathrm{HK}, \mathrm{PR}$, and HS contributed to the experiment design. HM, MS, ST, RT, HK, and PR participated in data collection. HM, TT, and JT contributed to the microCT measurement and analysis. HM and PR performed statistical analyses, interpreted the data, and drafted the manuscript. HS critically reviewed the paper. All authors read and approved the final manuscript. 


\section{Competing interests}

The authors declare that they have no competing interests.

Received: 6 October 2010 Accepted: 17 January 2011

Published: 17 January 2011

\section{References}

1. Beamer WG, Donahue LR, Rosen CJ, Baylink DJ: Genetic variability in adult bone density among inbred strains of mice. Bone 1996, 18:397-403.

2. Rosen CJ, Bouxsein ML: Mechanisms of disease: Is osteoporosis the obesity of bone? Nat Clin Pract Rheumatol 2006, 2:35-43.

3. Gimble JM, Zvonic S, Floyd ZE, Kassem M, Nuttall ME: Playing with bone and fat. J Cell Biochem 2006, 98:251-266.

4. Jebb SA, Moore MS: Contribution of a sedentary lifestyle and inactivity to the etiology of overweight and obesity: Current evidence and research issues. Med Sci Sports Exerc 1999, 31:S534-541.

5. Zhao LJ, Jiang H, Papasian CJ, Maulik D, Drees B, Hamilton J, Deng HW: Correlation of obesity and osteoporosis: Effect of fat mass on the determination of osteoporosis. J Bone Miner Res 2008, 23:17-29.

6. Weisberg SP, McCann D, Desai M, Rosenbaum M, Leibel RL, Ferrante AW Jr: Obesity is associated with macrophage accumulation in adipose tissue. J Clin Invest 2003, 112:1796-1808.

7. Seibel MJ: Nutrition and molecular markers of bone remodelling. Curr Opin Clin Nutr Metab Care 2002, 5:525-531.

8. Watkins BA, Li Y, Allen KG, Hoffmann WE, Seifert MF: Dietary ratio of (n-6)/ $(n-3)$ polyunsaturated fatty acids alters the fatty acid composition of bone compartments and biomarkers of bone formation in rats. J Nutr 2000, 130:2274-2284

9. Tam WY, Chook P, Qiao M, Chan LT, Chan TY, Poon YK, Fung KP, Leung PC, Woo KS: The efficacy and tolerability of adjunctive alternative herbal medicine (salvia miltiorrhiza and pueraria lobata) on vascular function and structure in coronary patients. J Altern Complement Med 2009, 15:415-421.

10. Corwin RL, Hartman TJ, Maczuga SA, Graubard BI: Dietary saturated fat intake is inversely associated with bone density in humans: Analysis of NHANES III. J Nutr 2006, 136:159-165.

11. Astrup A, Dyerberg J, Selleck M, Stender S: Nutrition transition and its relationship to the development of obesity and related chronic diseases. Obes Rev 9 Suppl 2008, 1:48-52

12. Dourmashkin JT, Chang GQ, Gayles EC, Hill JO, Fried SK, Julien C, Leibowitz SF: Different forms of obesity as a function of diet composition. Int J Obes (Lond) 2005, 29:1368-1378

13. Reich MS, Jarvis JP, Silva MJ, Cheverud JM: Genetic relationships between obesity and osteoporosis in LGXSM recombinant inbred mice. Genet Res 2008, 90:433-444.

14. Pollock NK, Laing EM, Baile CA, Hamrick MW, Hall DB, Lewis RD: Is adiposity advantageous for bone strength? A peripheral quantitative computed tomography study in late adolescent females. Am J Clin Nutr 2007, 86:1530-1538.

15. Leonard MB, Shults J, Wilson BA, Tershakovec AM, Zemel BS: Obesity during childhood and adolescence augments bone mass and bone dimensions. Am J Clin Nutr 2004, 80:514-523.

16. Gomez-Ambrosi J, Rodriguez A, Catalan V, Fruhbeck G: The bone-adipose axis in obesity and weight loss. Obes Surg 2008, 18:1134-1143.

17. Reid IR: Relationships between fat and bone. Osteoporos Int 2008, 19:595-606.

18. Daly RM: The effect of exercise on bone mass and structural geometry during growth. Med Sport Sci 2007, 51:33-49.

19. Wu J, Wang XX, Higuchi M, Yamada K, Ishimi Y: High bone mass gained by exercise in growing male mice is increased by subsequent reduced exercise. J Appl Physiol 2004, 97:806-810.

20. Ma H, Leskinen T, Alen M, Cheng S, Sipilä S, Heinonen A, Kaprio J, Suominen $\mathrm{H}$, Kujala UM: Long-term leisure time physical activity and properties of bone: A twin study. J Bone Miner Res 2009, 24:1427-1433.

21. Ma H, Torvinen S, Silvennoinen M, Rinnankoski-Tuikka R, Kainulainen $H$, Morko J, Peng Z, Kujala UM, Rahkila P, Suominen H: Effects of diet-induced obesity and voluntary wheel running on bone properties in young male C57BL/6J mice. Calcif Tissue Int 2010, 86:411-419.

22. Dufresne T: Segmentation techniques for analysis of bone by threedimensional computed tomographic imaging. Technol Health Care 1998, 6:351-359.
23. Waarsing $J \mathrm{H}$, Day $\mathrm{JS}$, Weinans $\mathrm{H}$ : An improved segmentation method for in vivo microCT imaging. J Bone Miner Res 2004, 19:1640-1650.

24. Lublinsky S, Ozcivici E, Judex S: An automated algorithm to detect the trabecular-cortical bone interface in micro-computed tomographic images. Calcif Tissue Int 2007, 81:285-293.

25. Buie HR, Campbell GM, Klinck RJ, MacNeil JA, Boyd SK: Automatic segmentation of cortical and trabecular compartments based on a dual threshold technique for in vivo micro-CT bone analysis. Bone 2007, 41:505-515.

26. Hildebrand T, Laib A, Muller R, Dequeker J, Ruegsegger P: Direct threedimensional morphometric analysis of human cancellous bone: Microstructural data from spine, femur, iliac crest, and calcaneus. J Bone Miner Res 1999, 14:1167-1674.

27. Mosekilde L, Ebbesen EN, Tornvig L, Thomsen JS: Trabecular bone structure and strength - remodelling and repair. J Musculoskelet Neuronal Interact 2000, 1:25-30.

28. Ding M, Odgaard A, Danielsen CC, Hvid I: Mutual associations among microstructural, physical and mechanical properties of human cancellous bone. J Bone Joint Surg Br 2002, 84:900-907.

29. Teo JC, Si-Hoe KM, Keh JE, Teoh SH: Relationship between CT intensity, micro-architecture and mechanical properties of porcine vertebral cancellous bone. In Clin Biomech. Volume 21. Bristol, Avon; 2006:235-244.

30. Burrows M, Liu D, Moore S, McKay H: Bone microstructure at the distal tibia provides a strength advantage to males in late puberty: A HR-pQCT study. J Bone Miner Res 2010, 25:1423-1432.

31. Roberts CK, Berger JJ, Barnard RJ: Long-term effects of diet on leptin, energy intake, and activity in a model of diet-induced obesity. J Appl Physiol 2002, 93:887-893.

32. Williams TD, Chambers JB, Roberts LM, Henderson RP, Overton JM: Dietinduced obesity and cardiovascular regulation in C57BL/6J mice. Clin Exp Pharmacol Physiol 2003, 30:769-778.

33. Iwaniec UT, Dube MG, Boghossian S, Song H, Helferich WG, Turner RT, Kalra SP: Body mass influences cortical bone mass independent of leptin signaling. Bone 2009, 44:404-412.

34. Galusca B, Zouch M, Germain N, Bossu C, Frere D, Lang F, LafageProust MH, Thomas T, Vico L, Estour B: Constitutional thinness: Unusual human phenotype of low bone quality. J Clin Endocrinol Metab 2008, 93:110-107.

35. Cobayashi F, Lopes LA, Taddei JA: Bone mineral density in overweight and obese adolescents. J Pediatr (Rio J) 2005, 81:337-342.

36. Aubertin-Leheudre M, Lord C, Labonte M, Khalil A, Dionne IJ: Relationship between sarcopenia and fracture risks in obese postmenopausal women. J Women Aging 2008, 20:297-308.

37. Braillon PM, Serban A: Bone mineral content and body composition in overweight children and adolescents. Pediatr Res 2007, 62:462-467.

38. Goseki-Sone M, Maruyama R, Sogabe N, Hosoi T: Effects of dietary lactose on long-term high-fat-diet-induced obesity in rats. Obesity (Silver Spring) 2007, 15:2605-2613.

39. Cao JJ, Gregoire BR, Gao H: High-fat diet decreases cancellous bone mass but has no effect on cortical bone mass in the tibia in mice. Bone 2009, 44:1097-1104.

40. Ionova-Martin SS, Do SH, Barth HD, Szadkowska M, Porter AE, Ager JW, Ager JW Jr, Alliston T, Vaisse C, Ritchie RO: Reduced size-independent mechanical properties of cortical bone in high-fat diet-induced obesity. Bone 2010, 46:217-225

41. Parhami F, Tintut Y, Beamer WG, Gharavi N, Goodman W, Demer LL: Atherogenic high-fat diet reduces bone mineralization in mice. J Bone Miner Res 2001, 16:182-188.

42. Hamrick MW, Ferrari SL: Leptin and the sympathetic connection of fat to bone. Osteoporos Int 2008, 19:905-912.

43. Thommesen L, Stunes AK, Monjo M, Grøsvik K, Tamburstuen MV, Kiøbli E, Lyngstadaas SP, Reseland JE, Syversen U: Expression and regulation of resistin in osteoblasts and osteoclasts indicate a role in bone metabolism. J Cell Biochem 2006, 99:824-834.

44. Gomez R, Lago F, Gomez-Reino J, Dieguez C, Gualillo O: Adipokines in the skeleton: influence on cartilage function and joint degenerative diseases. J Mol Endocrinol 2009, 43:11-18.

45. Leibowitz SF, Chang GQ, Dourmashkin JT, Yun R, Julien C, Pamy PP: Leptin secretion after a high-fat meal in normal-weight rats: Strong predictor of long-term body fat accrual on a high-fat diet. Am J Physiol Endocrinol Metab 2006, 290:E258-267. 
46. Gallou-Kabani C, Vige A, Gross MS, Rabès JP, Boileau C, Larue-Achagiotis C Tomé $\mathrm{D}$, Jais JP, Junien C: C57BL/6J and A/J mice fed a high-fat diet delineate components of metabolic syndrome. Obesity (Silver Spring) 2007, 15:1996-2005.

47. Elefteriou F, Takeda S, Ebihara K, Magre J, Patano N, Kim CA, Ogawa Y, Liu X, Ware SM, Craigen WJ, Robert JJ, Vinson C, Nakao K, Capeau J, Karsenty G: Serum leptin level is a regulator of bone mass. Proc Natl Acad Sci USA 2004, 101:3258-3263.

48. Koerner A, Kratzsch J, Kiess W: Adipocytokines Leptin-the classical, resistin-the controversical, adiponectin-the promising, and more to come. Best Pract Res Clin Endocrinol Metab 2005, 19:525-546.

49. Nordstrom SM, Carleton SM, Carson WL, Eren M, Phillips CL, Vaughan DE: Transgenic over-expression of plasminogen activator inhibitor-1 results in age-dependent and gender-specific increases in bone strength and mineralization. Bone 2007, 41:995-1004.

50. Amizuka N, Shimomura J, Li M, Seki Y, Oda K, Henderson JE, Mizuno A, Ozawa $\mathrm{H}$, Maeda T: Defective bone remodelling in osteoprotegerindeficient mice. J Electron Microsc (Tokyo) 2003, 52:503-51.

51. Palombaro KM: Effects of walking-only interventions on bone mineral density at various skeletal sites: A meta-analysis. J Geriatr Phys Ther 2005, 28:102-107.

52. Martyn-St James M, Carroll S: Meta-analysis of walking for preservation of bone mineral density in postmenopausal women. Bone 2008, 43:521-531.

53. Yu CC, Sung RY, So RC, Lui KC, Lau W, Lam PK, Lau EM: Effects of strength training on body composition and bone mineral content in children who are obese. J Strength Cond Res 2005, 19:667-672.

54. Hinton PS, Rector RS, Thomas TR: Weight-bearing, aerobic exercise increases markers of bone formation during short-term weight loss in overweight and obese men and women. Metabolism 2006, 55:1616-1618.

55. Villareal DT, Shah K, Banks MR, Sinacore DR, Klein S: Effect of weight loss and exercise therapy on bone metabolism and mass in obese older adults: A one-year randomized controlled trial. J Clin Endocrinol Metab 2008, 93:2181-2187.

56. Hamrick MW, Skedros JG, Pennington C, McNeil PL: Increased osteogenic response to exercise in metaphyseal versus diaphyseal cortical bone. J Musculoskelet Neuronal Interact 2006, 6:258-263.

57. Welch JM, Turner CH, Devareddy L, Arjmandi BH, Weaver CM: High impact exercise is more beneficial than dietary calcium for building bone strength in the growing rat skeleton. Bone 2008, 42:660-668.

58. Plochocki JH, Rivera JP, Zhang C, Ebba SA: Bone modeling response to voluntary exercise in the hindlimb of mice. J Morphol 2008, 269:313-318.

59. Nagasawa S, Honda A, Sogo N, Umemura Y: Effects of low-repetition jump exercise on osteogenic response in rats. J Bone Miner Metab 2008, 26:226-230.

60. Halloran BP, Ferguson VL, Simske SJ, Burghardt A, Venton LL, Majumdar S: Changes in bone structure and mass with advancing age in the male C57BL/6J mouse. J Bone Miner Res 2002, 17:1044-1050.

61. Somerville JM, Aspden RM, Armour KE, Armour KJ, Reid DM: Growth of C57BL/6 mice and the material and mechanical properties of cortical bone from the tibia. Calcif Tissue Int 2004, 74:469-475.

62. Mori T, Okimoto N, Sakai A, Okazaki Y, Nakura N, Notomi T, Nakamura T: Climbing exercise increases bone mass and trabecular bone turnover through transient regulation of marrow osteogenic and osteoclastogenic potentials in mice. J Bone Miner Res 2003, 18:2002-2009.

63. Bourrin S, Genty C, Palle S, Gharib C, Alexandre C: Adverse effects of strenuous exercise: A densitometric and histomorphometric study in the rat. J Appl Physiol 1994, 76:1999-2005.

64. Wallace JM, Rajachar RM, Allen MR, Bloomfield SA, Robey PG, Young MF, Kohn DH: Exercise-induced changes in the cortical bone of growing mice are bone- and gender-specific. Bone 2007, 40:1120-1127.

65. Warren GL, Moran AL, Hogan HA, Lin AS, Guldberg RE, Lowe DA: Voluntary run training but not estradiol deficiency alters the tibial bone-soleus muscle functional relationship in mice. Am J Physiol Regul Integr Comp Physiol 2007, 293:R2015-R2026.

66. Maimoun L, Sultan C: Effects of physical activity on bone remodeling. Metabolism

67. Luu YK, Capilla E, Rosen CJ, Gilsanz V, Pessin JE, Judex S, Rubin CT: Mechanical stimulation of mesenchymal stem cell proliferation and differentiation promotes osteogenesis while preventing dietary-induced obesity. J Bone Miner Res 2009, 24:50-61.
68. Kyung TW, Lee JE, Van Phan T, Yu R, Choi HS: Osteoclastogenesis by bone marrow-derived macrophages is enhanced in obese mice. J Nutr 2009, 139:502-506.

doi:10.1186/1743-7075-8-1

Cite this article as: Ma et al:: Effects of diet-induced obesity and voluntary wheel running on the microstructure of the murine distal femur. Nutrition \& Metabolism 2011 8:1.

\section{Submit your next manuscript to BioMed Central and take full advantage of:}

- Convenient online submission

- Thorough peer review

- No space constraints or color figure charges

- Immediate publication on acceptance

- Inclusion in PubMed, CAS, Scopus and Google Scholar

- Research which is freely available for redistribution

Submit your manuscript at www.biomedcentral.com/submit
C Biomed Central 